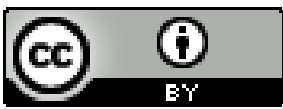

\title{
MARIANA QUER SER LIVRE: TRÁFICO DE ESCRAVIZADOS E NAÇÃO EM BELÉM (1700-1750)
}

\begin{abstract}
Marley Antonia Silva da Silva ${ }^{1}$
Resumo: A busca por liberdade de Mariana, uma escravizada mina "courana" que vivia em Belém do Grão-Pará, nos idos de 1738 é analisada nesse artigo. Na primeira metade do século XVIII o tráfico transatlântico e a presença africana em Belém são caracterizados pela historiografia como pouco expressivos, uma vez que as populações indígenas foram massivamente utilizadas como trabalhadores, especialmente até 1750 no Grão-Pará. É nesse cenário que Mariana busca comprar sua alforria. A documentação do Arquivo Histórico Ultramarino foi utilizada para desenvolver as ideias contidas neste trabalho. $\mathrm{O}$ debate sobre nação, tráfico, liberdade emergem do requerimento de Mariana e são aqui apresentados.
\end{abstract}

Palavras Chaves: Tráfico transatlântico, nação, liberdade, Grão-Pará.

\section{MARIANA WANTS TO BE FREE: SLAVE TRADE AND NATION IN BELÉM} (1700-1750)

Abstract: Mariana's search for freedom, an enslaved "courana" mine that lived in Belém do Grão Pará, in 1738 is analyzed in this article. In the first half of the 18th century, transatlantic trafficking and the African presence in Belém are characterized by historiography as not very expressive, since indigenous populations were massively used as workers, especially until 1750 in Grão Pará. It is in this scenario that Mariana seeks to buy her manumission. The documentation of the Overseas Historical Archive was used to develop the ideas contained in this work. The debate about nation, trafficking, freedom emerges from Mariana's request and is presented here.

Keywords: Transatlantic traffic, nation, freedom, Grão Pará.

\section{MARIANA QUIERE SER LIBRE: COMERCIO DE ESCLAVOS Y NACIÓN EN BELÉM (1700-1750)}

Resumen: La búsqueda de libertad de Mariana, una mina esclava "courana" que vivió en Belém do Grão Pará, en 1738 se analiza en este artículo. En la primera mitad del

\footnotetext{
${ }^{1}$ Doutoranda em História pelo PPHIST/UFPa, docente do IFPa/Tucuruí, coordenadora do grupo de pesquisa Linguagem, Cultura e Educação na Amazônia, membro do grupo de Estudos e Pesquisas da Escravidão e Abolicionismo na Amazônia, membro do grupo de História do Livro Didático na Amazônia. E-mail: marleyhist@yahoo.com.br
}

Revista da ABPN • v. 12, n. Ed. Especial - Caderno Temático: "Africanos, escravizados, libertos biografias, imagens e experiências atlânticas" • agosto de 2020, p. $10-26$ 
siglo XVIII, el tráfico transatlántico y la presencia africana en Belém se caracterizan por la historiografía como poco expresiva, ya que las poblaciones indígenas fueron utilizadas masivamente como trabajadores, especialmente hasta 1750 en Grão Pará. Es en este escenario que Mariana busca comprarla. manumisión. La documentación del Archivo Histórico de Ultramar se utilizó para desarrollar las ideas contenidas en este trabajo. El debate sobre la nación, el tráfico y la libertad surge de la solicitud de Mariana y se presenta aquí.

Palabras clave: Tráfico transatlántico, nación, libertad, Grão Pará.

\section{MARIANA VEUT ÊTRE LIBRE: TRAITE DES ESCLAVES ET NATION À BELEM (1700-1750)}

Résumé: La quête de liberté de Mariana, une mine de «courana» asservie qui vivait à Belém do Grão Pará, en 1738, est analysée dans cet article. Dans la première moitié du XVIIIe siècle, le trafic transatlantique et la présence africaine à Belém sont caractérisés par l'historiographie comme peu expressifs, les populations indigènes étant massivement utilisées comme ouvrières, notamment jusqu'en 1750 à Grão Pará. C'est dans ce scénario que Mariana cherche à l'acheter. manumission. La documentation des archives historiques d'outre-mer a été utilisée pour développer les idées contenues dans ce travail. Le débat sur la nation, le trafic, la liberté émerge de la demande de Mariana et est présenté ici.

Mots-clés: trafic transatlantique, nation, liberté, Grão Pará.

\section{DA COSTA DA MINA A BELÉM DO GRÃO PARÁ}

Na cidade do Grão Pará, como era chamada Belém, Mariana, mulher africana, da nação corana, desejava ser livre. Tentou pagar alforria, ao seu senhor Augusto Domingues de Sequeira, mas, "por não querer este "conceder" sua liberdade embaraçou lhe por todos os meios aos quais não pode lhe fiar a suplicante"2. A mulher, descrita como "preta do gentio da Guiné", enviou requerimento ao rei, pedindo para que se admitisse sua alforria. O documento de Mariana foi enviado a Portugal em 1738. Está registrado que Mariana já servia ao senhor cerca de seis anos. Todavia, estava acometida de uma enfermidade, por isso afirmava que tal motivo, a impossibilitava de poder continuar na escravidão. Havia encontrado uma pessoa, que "movida por

${ }^{2}$ REQUERIMENTO da preta do gentio da Guiné da nação corana, Mariana, escrava de Augusto Domingues de Sequeira, para o rei [D. João V], solicitando que se lhe autorize a alforria, visto ter uma pessoa que lhe pagará a mesma. Data: 28 de março de 1738. AHU_ACL_CU_013, Cx. 21, D. 1948.

Revista da ABPN • v. 12, n. Ed. Especial - Caderno Temático: "Africanos, escravizados, libertos biografias, imagens e experiências atlânticas” • agosto de 2020, p. $10-26$ 
compaixão lhe ofereceu o dinheiro de sua alforria"; como não resolveu a questão com a justiça local, enviou o requerimento a Portugal.

Mariana foi descrita como "preta do gentio de Guiné de nação Corana". São informações indicativas de procedência na primeira informação, e da identidade étnica na segunda. No Brasil do século XVI registrava se "gentil da Guiné" ou "negro da Guiné” para referir-se genericamente aos africanos e tal designação perdurou até a primeira metade do século XVII. A historiadora Maria Oliveira (1997, p.37) destaca que "mais do que um registro de procedência, estas expressões queriam significar a condição mesma de escravo na linguagem corrente da época”.

Em se tratando de Guiné em termos espaciais, o historiador José da Silva Horta (2009, p.2) afirma que durante o século XVI, a imprecisão na descrição, fazia parte inclusive da documentação administrativa, o autor destaca, que essa indeterminação espacial (especialmente durante o século XVI), “cujos significados podiam, consoante o ponto de vista em causa, comportar oscilações relativamente às sub-áreas de comércio que incluíam ou excluíam” (HORTA, 2009, p.3). Tal inexatidão, favorecia às práticas econômicas portuguesas, uma vez que sem obedecer a princípios geográficos bem definidos, poderiam comerciar em vasto território que poderia ser descrito como Guiné. De maneira que o espaço frequentado pelos lusos e seus descendentes, seria Guiné, mesmo que o alcance dessa presença nos séculos XVI e XVII não seja bem nítida. ${ }^{3}$ Mas, o que era a Guiné nos primeiros tempos do tráfico de escravizados africanos? De acordo ainda com a historiadora Maria de Oliveira:

No início, para os portugueses, a Guiné teria se restringido ao litoral da costa ocidental africana, que tinha como centro comercial a feitoria de Cachéu, subordinada as ilhas de Cabo Verde. Esta era a área descrita nos contratos de arrendamento do século XV. Entretanto, à medida em que a expansão do comércio português avançou para o sul, o termo passou a ser também utilizado para designar as partes do litoral então conhecidas como Costa da Pimenta, Costa do Marfim, Costa do Ouro e Costa dos Escravos. Assim, toda a África Ocidental ao norte do Equador, do Rio Senegal ao Gabáo, era conhecida então como a Guiné (OLIVEIRA, 1997, p. 39)

\footnotetext{
3 Ver: SANTOS, Maria Emília Madeira e BALENO Ilídio Cabral: linha de atracção, repulsão e compressão (Arquipélagos e Costa Ocidental Africana), Cascais, Patrimonia, 1998 (sep. Limites do Mar e da Terra, Actas da VIII Reunião Internacional de História da Náutica e Hidrografia, pp. 147-152), p. 147.
}

Revista da ABPN • v. 12, n. Ed. Especial - Caderno Temático: "Africanos, 
Como se pode observar a Costa dos Escravos também foi entendida como Guiné, essa denominação recebida do século XVI ao XIX ${ }^{4}$, corresponde as zonas costeiras dos atuais Benim, Togo e Nigéria ocidental. O golfo do Benim estende-se do Volta até o rio Nun, de acordo com as informações geográficas assumidas por David Eltis no memorial digital, Slavevoyages, que levanta questões sobre o maior comércio de escravos da história 5 . Foi dos portos do golfo do Benim que saíram os "pretos minas”, segundo Mariza Soares (2007); a escravizada Mariana foi descrita como sendo da nação corana, era uma mulher africana mina.

Os nomes de nação não são homogêneos e podem referir-se a portos de embarque, reinos, etnia, ilhas ou cidades. Segundo Nicolau Pares, tais denominações foram utilizadas por traficantes e senhores de escravos, servindo aos seus interesses de classificação administrativa e de controle. Em muitos casos, os portos ou área geográfica de embarque parece ter sido um dos critérios prioritários na elaboração dessas categorias (Mina, Angola, Cabo Verde, São Tomé). Dessa forma, tais denominações não correspondem necessariamente às auto declarações étnicas utilizadas pelos africanos em suas regiões de origem (PARES, 2007, p.24-25).

De acordo com a historiadora Mariza Soares é preciso distinguir o uso do termo "nação" como emblema de identidade de procedência (nação angola, nação mina) e o termo do uso "nação" enquanto emblema de identidade étnica: a nação rebolo-tunda, nação mina-sarubu, nação mina-maki, e tantas outras (SOARES, 2000, p.114-189). A perspectiva de nação, enquanto conceito de grupo de procedência, onde nação indica um agrupamento de população africana, sem necessariamente pertencerem ao mesmo grupo étnico, mas, que agrupa considerando elementos comuns, o historiador João José Reis chamou metaforicamente de "guarda-chuva" que pode resguardar uma variedade de povos (REIS, 1986, 235-281).

Para Mariza Soares,

\footnotetext{
${ }^{4}$ Ver: ELLIS, A. B. (1894). The Yoruba-speaking people of the Slave Coast of West Africa. Londres: Chapman and Hall. 420 páginas

Law, Robin (1991). The Slave Coast of West Africa - The impact of trade slave. Oxford: Oxford Studies. 376 páginas

${ }^{5}$ Ver: https://www.slavevoyages.org
}

Revista da ABPN • v. 12, n. Ed. Especial - Caderno Temático: "Africanos, escravizados, libertos biografias, imagens e experiências atlânticas” • agosto de 2020, p. $10-26$ 
uso dos termos "preta-mina", "nação angola" e "escravos de Guiné". Essas expressões costumam acompanhar o nome dos escravos ou ser incorporadas a eles: Antônio Mina, Manoel do Gentio de Guiné, Elório Cabinda. Em todos os casos, o nome traz a marca de uma designação de grupo (SOARES, 1998, p.1).

Mariana era preta da nação Corana, como menciona o documento, que certamente não foi escrito pela africana, e sim por mãos alheias, como bem disse a historiadora Silvia Rachi (2016). Escrever no período colonial era privilégio de grupo seleto. A identidade associada à escravizada africana: "corana”, entendida aqui como um marcador de procedência, remete a um lugar específico em território do continente africano, a Costa da Mina, África Ocidental. O lugar no qual Mariana pode ter vivido, a "terra de Courá" foi apontada por alguns historiadores. Em Minas Gerais as pessoas traficadas da "terra de Courá" faziam parte expressivas das irmandades religiosas (PINHEIRO, 2006, p. 136). Nas palavras de Pierre Verger, em seu livro Fluxo e Refluxo, os couranos eram "pessoas conhecidas sob o nome de Curamo, nome dado à lagoa das proximidades de Lagos", ou Onim, porto no litoral da atual Nigéria. Esse autor menciona que, os coranos são descritos como inimigos do Rei de Daomé e um documento datado de 1767 divulgava uma invasão de "coiranos" a Ajudá (VERGER, 1987, p. 207).

A historiadora Mariza Soares investigou exaustivamente os "pretos mina" e quando menciona as rotas pelas quais teriam seguido os escravizados couranos, aponta que seriam oriundos de uma localidade chamada Aledjo Koura, ao norte de Bassila e próxima às nascentes do rio Mono, situada no atual Togo. Ainda segundo a estudiosa, o percurso da suposta rota terrestre que ligava esse interior aos portos do litoral onde os couranos foram embarcados eram Ajudá e Jaquem (SOARES, 2007, p.80-82).

Mariana foi embarcada no golfo do Benim. Todavia, as pessoas tornadas cativas nessa região, embarcaram em navios geralmente destinados aos portos da Bahia, Recife e em menor volume no Rio de Janeiro (VERGER, 1987; ACIOLLI, 2008; FLORENTINO, 1997/2004). Por tanto, não seguiu o percurso da maioria dos escravizados que vieram de África aos portos do Pará e Maranhão na primeira metade do século XVIII.

Revista da ABPN • v. 12, n. Ed. Especial - Caderno Temático: "Africanos, escravizados, libertos biografias, imagens e experiências atlânticas" • agosto de 2020, p. $10-26$ 
O período que envolve as últimas décadas do século XVII até a primeira metade do século XVIII (1680 até 1755) é marcado por trânsito irregular de navios negreiros entre Grão-Pará e África. Remetendo a esse período e aos povos escravizados africanos, Manuel Nunes Pereira afirma que "não chegavam em massa para inundar as plantações do Norte" (1949, p.510).

No que diz respeito ao estudo do tráfico de escravizados para o Estado do GrãoPará e Rio Negro é necessário considerar que desde o início da colonização, Pará e Maranhão estiveram extremamente ligados, administrativamente. O Estado do Maranhão teve muitas modificações na nomenclatura administrativa. De acordo com Patrícia Sampaio, quando foi instituído como unidade administrativa diferente do Brasil em 1621, estava diretamente ligado a Lisboa. Instalado em 1621, o Estado do Maranhão foi instituído como unidade administrativa diferente do Brasil em 1626, foi temporariamente extinto em 1642 e logo reconstituído em 1654, com a denominação de Estado do Maranhão e Grão-Pará, sendo São Luís sua capital. Tanto a extensão quanto os limites do Estado permaneceram o mesmo, pelo menos até 1656, quando a capitania do Ceará passou a subordinação do Brasil (SAMPAIO, 2003, p.123).

Durante o reinado de D. José I (1750-1777) a separação foi mantida, entretanto a região sofreu reordenamentos. Em 1751, foi extinto o Estado do Maranhão e Grão-Pará e, em seu lugar, foi instalado o Estado do Grão-Pará e Maranhão, sediado em Belém, compreendia as capitanias do Grão-Pará, Maranhão e Piauí e - a partir de 1755 - a de São José do Rio Negro.

$\mathrm{Na}$ investigação sobre trânsito de escravizados entre a costa africana e o Estado do Maranhão e Grão- Pará, ocorrido entre 1707-1750, Benedito Barbosa (2009) corrobora com argumentos já apontados por Daniel Domingues da Silva (2008) de que o tráfico constituiu um negócio de base triangular, com forte apoio da Coroa portuguesa, que colaborou ao financiar e proporcionar a estrutura necessária ao comércio de pessoas escravizadas oriundas de África.

Revista da ABPN • v. 12, n. Ed. Especial - Caderno Temático: "Africanos, escravizados, libertos biografias, imagens e experiências atlânticas" • agosto de 2020, p. $10-26$ 
Benedito Barbosa (2009) analisou também elementos internos, como as epidemias, e seus impactos no mencionado comércio. Ressalta o historiador que nos períodos de epidemias os moradores e as autoridades discursavam sobre a importância do africano para o crescimento econômico da região amazônica, fato examinado nos constantes pedidos de escravizados oriundos de África, como alternativa para suprir a carência de mão de obra que a região vivenciava.

Nesta direção Rafael Chambouleyron (2006, p.81) aponta que "o tráfico negreiro ao longo do século XVII e início do século XVIII se organizou a partir de pressupostos diferentes do tráfico brasileiro". O autor chama atenção para o fato de que o tráfico para o Maranhão e Grão-Pará era organizado a partir da Coroa, diferentemente de outras praças como Bahia, Pernambuco ou Rio de Janeiro.

Os dados relativos ao século XVII e a primeira metade do século XVIII são mais escassos, as dificuldades de acesso às fontes, bem como o caráter fragmentário das mesmas foram elementos que limitaram as investigações no mencionado período. Todavia, este quadro já vem sendo modificado. Em pesquisa que se estende de 1671 a 1705, Chambouleyron, examina as particularidades da migração forçada de africanos para o Estado do Maranhão, na sua investigação, o historiador indica que, pouco menos de mil cativos africanos foram trazidos para o Estado do Maranhão por meio do tráfico legal, autor evidencia ainda que este número não é pequeno se for pensado no conjunto total dos habitantes (CHAMBOULEYRON, 2006, pp.102-105).

Benedito Barbosa (2008; 2009), preocupado em investigar o trânsito de africanos para a Amazônia Colonial durante o reinado de D. João V (1707-1750), buscou na pesquisa, enfatizar um recorte pouco privilegiado pela historiografia que costuma centrar as investigações na segunda metade do século XVIII, com as políticas pombalinas. $\mathrm{O}$ autor no que concerne aos números do tráfico dialoga fundamentalmente com os dados de Kátia Mattoso (2003, p.32) e de Daniel Domingues Silva (2008, p.481), os dados do primeiro autor são bem semelhantes ao do último, ainda que Benedito Barbosa faça um elaborado cruzamento de diversos conjuntos documentais, ambos chegam ao total de 959 escravizados, para o período que se estende de 17071750. Esses trabalhadores africanos complementavam a mão de obra, pois, naquele momento eram os trabalhadores indígenas, que faziam as atividades econômicas

Revista da ABPN • v. 12, n. Ed. Especial - Caderno Temático: "Africanos, escravizados, libertos biografias, imagens e experiências atlânticas” • agosto de 2020, p. $10-26$ 
girarem, e eram largamente utilizados pelos moradores, sendo impossível falar de trabalhadores neste contexto sem considerá-los.

Para Maria Celestino de Almeida (1988, p.105) “características peculiares da colonização da Amazônia permitiram que a população indígena fosse utilizada como mão-de-obra predominante por um período mais longo". O "gentil" constituiu a mãode-obra fundamental para a colonização portuguesa na região, ao ponto de causar sérios conflitos entre religiosos e moradores. Como disse Nádia Farage, a disputa pelo acesso e controle da mão de obra indígena é o fio que tece a história política (1991, p.6). Essa afirmação é especialmente certeira para a primeira metade do século XVIII.

O historiador Daril Alden (1985, p.431) ressalta o papel fundamental das populações indígenas também como trabalhadores "desde os princípios da colonização até 1750 ". Livres ou cativos as populações indígenas oportunizaram a riqueza gerada na Amazônia Colonial. Existiam diferentes formas de ter acesso a estes trabalhadores, o recrutamento nos idos de 1680-1755 poderia ocorrer através dos descimentos, resgates ou guerras justas (DIAS; BOMBARDI, 2016; SIQUEIRA, 2017).

\section{CONEXÕES ENTRE PORTOS DE ÁFRICA E BELÉM COLONIAL}

A conexão entre o norte do continente africano e o norte da América Portuguesa perdurava desde o século XVII, pois buscou-se uma conexão entre Maranhão e Guiné. De acordo com Rafael Chambouleyron (2006, p.95), tal conexão tinha por objetivo resolver os problemas decorrentes da proibição da escravização e da escravidão indígenas no Estado do Maranhão e consolidar a presença portuguesa na Guiné. Todavia, o termo Guiné ou Guiné Portuguesa ou “o uso mais restrito de "Guiné” e termos associados que se vulgarizaram não estavam isentos de ambiguidades e estavam longe de serem neutros, correspondendo a diferentes, e por vezes contrastantes percepções do espaço africano" (HORTA, 2009, p.2).

A historiografia dividiu a zona costeira atlântica em Guiné Superior ou Alta Guiné, indo do Senegal ao Cabo de Palmas, e Guiné Inferior ou Baixa Guiné, indo do Cabo de Palmas ao delta do Níger, na baía do Biafra. Essa é a delimitação empregada pelo historiador Walter Rodney (1970), no seu clássico trabalho "A History of the

Revista da ABPN • v. 12, n. Ed. Especial - Caderno Temático: "Africanos, escravizados, libertos biografias, imagens e experiências atlânticas" • agosto de 2020, p. $10-26$ 
Upper Guinea Coast 1545-1800”, onde a expressão "Upper Guinea Coast” designa a costa compreendida entre a Gâmbia e o Cabo Mount. Na leitura espacial e histórica de Carlos Lopes (2005), a Alta Guiné seria o espaço entre a Gâmbia e a Serra Leoa (LOPES, 2005).

Embora franceses e ingleses fossem negociantes costumazes de escravizados na Alta Guiné; foram os portugueses os maiores e principais traficantes na região, e mantiveram o tráfico da Guiné com São Luís e Belém, aliás, um comércio que foi duradouro e atravessou séculos. As viagens transatlânticas mais curtas de todas as travessias atlânticas eram as que ocorriam entre norte do litoral africano e o norte do Brasil, ao tratar sobre as rotas em seu trabalho sobre o tráfico na primeira metade do século XVIII, Benedito Barbosa destacou:

\begin{abstract}
A rota negreira tornou-se outra característica que diferenciou o tráfico negreiro. Os escravos entrados na Amazônia vieram em sua maioria do norte da África Ocidental principalmente da região da Senegâmbia e da Costa da Mina, e também do Golfo do Benin. Essa rota acontecia desde o século XVII e prosseguiu no século seguinte (BARBOSA, p.131).
\end{abstract}

Todavia, o trabalho de Barbosa, não aponta nenhuma entrada de navio vindo da Costa da Mina que tenham encostado nos portos de Belém durante 1707-1750. Todos os navios oriundos dessa região que o historiador evidenciou foram direcionados a São Luís. Para o norte da América Portuguesa, o comércio de gente escravizada, ocorreu reiteradamente entre Alta Guiné, Maranhão e Pará, o que se evidencia notadamente, nas décadas finais do século XVII e primeira metade do século XVIII (HAWTHORNE, 2010,p.52-53). Tais portos de procedência já haviam sido apontados por (CHAMBOULEYRON, 2006, p.97), "sem dúvida chama a atenção para o século XVII, o que é comparável com a experiência de meados do século XVIII é a procedência dos escravos, fundamentalmente da Guiné e da Costa da Mina”.

Mariana atravessou o Atlântico e chegou ao porto de Belém. Em qual navio? Em que ano tal navio teria atracado? É difícil dizer com mínima precisão, a escravizada como informou o documento, já servia cerca de seis anos Augusto Domingues de Sequeira, é provável que tenha chegado a Belém, acompanhando o mesmo senhor como

Revista da ABPN • v. 12, n. Ed. Especial - Caderno Temático: "Africanos, escravizados, libertos biografias, imagens e experiências atlânticas" • agosto de 2020, p. $10-26$ 
escravizada doméstica. Não era incomum escravizados que atravessavam o Atlântico com seus senhores e desembarcavam no mercado do Ver o Peso em Belém.

\section{MARIANA BUSCANDO LIBERDADE}

Mariana era uma "preta mina" que veio da "terra de Courá". Segundo (Karasch, 1987, p.26), no Rio de Janeiro, em determinado momento o termo "mina" tinha adquirido um significado adicional que caracterizava-os como "orgulhosos, indômitos e corajosos muçulmanos de língua árabe que eram escravos alfabetizados, inteligentes, capacitados e cheios de energia - e que trabalhavam duro para comprar sua liberdade". Também Beatriz Mamigonian (2000) evidenciou esse aspecto ao afirmar que, pretos minas estavam associados a resistência e luta por liberdade. Mariana era uma mulher negra e como nos lembra a historiadora Claudia Pons Cardoso (CARDOSO, 2018, p.318): "Mulheres negras, porém, historicamente têm questionado poderes, desafiado estereótipos, preconceitos e representações negativas, enfrentado violências, desigualdades e discriminações". E isso sem dúvida remonta ainda os períodos de escravização.

O caso da preta mina Mariana, talvez seja o primeiro registro localizado de pedido formal de alforria, de uma africana na primeira metade do século XVIII em Belém, onde o documento evidencia a nação de quem solicita liberdade. Embora, antes disso possa ter havido outros requerimentos de liberdade, como no caso de António de Melo, pardo, praça de soldado do Estado do Maranhão, escravizado de Gregório de Melo e Magalhães, morador na cidade do Pará. No entanto, há diferenças bem nítidas nos dois pedidos, haja vista que, Mariana é identificada como africana e António como pardo, a mulher foi quem solicitou a liberdade, no caso de Antônio que era militar, quem solicitou foi seu senhor, Gregório Magalhães. Sendo pardo provavelmente António havia nascido no norte da América Portuguesa, ${ }^{6}$ já Mariana nasceu em África.

Os escravizados pela ótica judicial, eram percebidos pelo direito civil como um bem semovente, nessa perspectiva, não possuíam nenhum direito ou obrigações

\footnotetext{
${ }^{6}$ REQUERIMENTO de Gregório de Melo e Magalhães, morador na cidade do Pará, para o rei [D. João V], solicitando a confirmação da alforria concedida a seu antigo escravo pardo, António de Melo, para que este possa continuar com a praça de soldado do Estado do Maranhão. Data 22 de fevereiro de 1725 AHU_ACL_CU_013, Cx. 8, D. 743.
}

Revista da ABPN • v. 12, n. Ed. Especial - Caderno Temático: "Africanos, escravizados, libertos biografias, imagens e experiências atlânticas” • agosto de 2020, p. $10-26$ 
jurídicas, no entanto, caso cometessem crimes, eram responsabilizados, respondiam processo e iam a julgamento; era uma perspectiva ambígua, ora coisificava a pessoa escravizada quando para lhe negar direitos, ora a tratava como responsável por suas ações quando para aplicar punições ${ }^{7}$. Todavia, os indivíduos oriundos de África e seus descendentes tornados cativos, sempre criaram formas múltiplas de resistências, reelaboraram, reorganizaram e transformaram, quando possível, o universo em que viveram (GOMES, 1997, p.30). E os caminhos da Justiça da época, foi qual Mariana trilhou em busca de sua liberdade.

De acordo com Fernanda Pinheiro em sua tese (2013), na América Portuguesa, "a alforria poderia ser gratuita, benefício equivalente a uma doação, ou onerosa, quando o escravizado, seu familiar ou um terceiro se encarregava de pagar por seu preço. $\mathrm{O}$ pagamento era feito à vista, a crédito ou parcelado". Marina almejava adquirir sua alforria pagando, escravizada possuía a quantia para conseguir seu intento. A africana sustentava que o valor pelo qual havia sido avaliada, foi doado "por pessoa movida por compaixão". Porém, seu senhor "por não querer dar-lhe liberdade, embaraçava lhe todos os meios", atitude considerada por ela injusta, motivo pelo qual enviou o requerimento ao rei. O preço que seria pago por sua alforria, não é mencionado no documento, havia, no entanto, alguém disposto a pagar, o que indica que a africana com certeza podia dispor de alguma rede de apoio em Belém.

Foram três os argumentos usados por Mariana para alegar que merecia alcançar sua alforria. Serviu bem ao seu senhor; possuía o valor de para sua remissão; estava acometida de uma enfermidade, que "a incapacita poder continuar na escravidão", este último argumento foi utilizado com frequência nos requerimentos de liberdade de escravizados africanos no Grão-Pará, durante o século XVIII. A alegada doença, poderia ser apenas um discurso para sensibilizar, também poderia ser fruto de atividades extenuantes e incapacitantes, ou ainda a africana poderia ter sido vítima de doenças, já que a região sofreu com diversas epidemias nesse período (CHAMBOULEYRON; BARBOSA; BOMBARDI; SOUSA, 2011).

\footnotetext{
${ }^{7}$ Ver: AZEVEDO, Elciene. “O direito dos escravos: lutas jurídicas e abolicionismo na província de São Paulo". Campinas (SP): Editora da Unicamp, 2010. p.65; LARA, Silvia Hunold. "Legislação sobre escravos africanos na América Portuguesa". Madrid, Fundación Histórica Tavera, 2000; Silvia Lara (org.), Ordenações Filipinas: Livro V, São Paulo, Companhia das Letras, 1999.
}

Revista da ABPN • v. 12, n. Ed. Especial - Caderno Temático: "Africanos, escravizados, libertos biografias, imagens e experiências atlânticas” • agosto de 2020, p. $10-26$ 
Os caminhos para galgar liberdade eram tortuosos, ser livre era uma conquista árdua, que as pessoas africanas e seus descendentes escravizados, sempre buscaram obter durante todo o período da escravização no Brasil. Haviam caminhos distintos na busca por ser livre. Ao se referir a Amazônia Colonial, o historiador Flávio Gomes, destacou que "fugas de escravos eram constantes em toda Amazônia inclusive, alcançando outra fronteiras coloniais”(GOMES, 1997, p.23). Fugas e formações de Quilombos, foram caminhos para liberdade, que obviamente, não obedeciam aos preceitos legais, naquele contexto, e o argumento colonial sobre a necessidade de mão de obra se ampliavam, segundo (ALDEN, 1985):

No início da década dos anos 1730, o cacau se tinha tornado o principal produto de exportação da Amazônia, posição que continuaria a ocupar por mais de um século. Os anos que ficam entre 1730-quando as estatísticas de exportação se tornaram disponíveis pela primeira vez- e 1822 (quando o Brasil se tornou independente) podem ser divididos em três períodos distintos. Em falta de melhores termos, o primeiro, que vai até 1755 , pode ser chamado "a primeira era do livre comércio". O segundo, que se estende de 1756 a 1777, foi o "período do monopólio", quando a economia da região Amazônica foi controlada pela famosa Companhia de Comércio do Grão-Pará e Maranhão. Esse controle cessou em 1778, quando a Companhia não conseguiu renovar seu contrato, começando uma nova era de livre comércio (ALDEN, 1974, p.31-32).

Mariana pede liberdade junto ao rei, no momento em que no Estado do Maranhão e Grão-Pará, multiplicam se os argumentos para uso da mão de obra de origem africana (Chambouleyron, 2004, p.111). Dentre os argumentos está a relação entre crescimento da agricultura e uso de trabalhadores escravizados de origem africana. A relação entre agricultura e braços negros é uma afirmativa que aparece na historiografia desde 1961, em Arthur Cezar Ferreira Reis, um pioneiro no tema, que ressaltou a relevância social dos africanos e de seus descendentes na região (REIS, 1961, p. 347).

O historiador Sidney Chalhoub (2009) ao tratar sobre liberdade, lembra que mesmo tendo conquistado a alforria, era difícil manter o estado de livre. Mariana buscava os caminhos da legalidade e da Justiça, para alcançar sua liberdade, pretendia comprar sua alforria, mas, para alcançar a emancipação, precisava contar com a anuência de Augusto Domingues de Sequeira, e isso não ocorreu, considerando que a

Revista da ABPN • v. 12, n. Ed. Especial - Caderno Temático: "Africanos, escravizados, libertos biografias, imagens e experiências atlânticas” • agosto de 2020, p. $10-26$ 
atitude de seu senhor era injusta, ela persiste com o processo e envia requerimento ao rei.

Referindo as ações de liberdade de índias e índios escravizados no Estado do Maranhão e Grão-Pará, primeira metade do século XVIII, as historiadoras Fernanda Bombardi e Luma Prado, evidenciam o percurso jurídico das ações de liberdade, movidas pelas populações indígenas, de certo, o processo de Marina seguiu percurso similar.

Em 1733, no Estado do Brasil, e em 1735, no Estado do Maranhão, as Ouvidorias tornaram-se espaços comum de apreciação da licitude da escravização de índias e índios, cabendo às sessões das Juntas a decisão final das apelações da decisão do Ouvidor. Caso alguma das partes permanecesse descontente, haveria ainda a possibilidade de recorrer à Casa de Suplicação no reino e, em último caso, diretamente ao rei. (BOMBARDI \& LUMA, 2016, p. 187).

Os principais responsáveis pelo governo da Justiça na América Portuguesa no decorrer do século XVIII, eram os Ouvidores Gerais e os Juízes de Fora, esses magistrados acumulavam competências judiciais e administrativas, com jurisdição para atuar na esfera civil e criminal (MELLO, 2014, p.359). Os Ouvidores Gerais eram nomeados pelo rei e circulavam em todo o território da comarca. Também os Ouvidores possuíam amplas competências administrativas. Por sua vez, o Juiz de Fora eram fixos e ocupavam um lugar no corpo de oficias das câmaras, em teoria representavam a primeira instância, tinham nomeação régia, recrutados entre os bacharéis em Direito.

$\mathrm{Na}$ perspectiva da Justiça, como mencionado, o rei era a última instância. Todavia, era comum a Coroa Portuguesa, interferir minimamente na autoridade do senhor de escravizado de origem africana. Não foi possível identificar se houve uma resposta ao requerimento vinda do reino, e por conseguinte, se Mariana conseguiu que seu requerimento fosse atendido positivamente por D. João V. É possível, porém, afirmar a existência e o protagonismo dessa mulher, africana mina escravizada e seu movimento na linha da história buscando liberdade para si recorrendo inclusive as possibilidades praticamente impossíveis das vias judiciais.

Revista da ABPN • v. 12, n. Ed. Especial - Caderno Temático: "Africanos, escravizados, libertos biografias, imagens e experiências atlânticas” • agosto de 2020, p. $10-26$ 


\section{REFERÊNCIAS BIBLIOGRÁFICAS}

ALDEN, Dauril. O Significado da Produção do Cacau na Região Amazônica. Belém: NAEA/ UFPA, 1974.

ALMEIDA, Maria Celestino de. Trabalho compulsório na Amazônia: séculos XVII-XVIII. Revista Arrabaldes, ano I, n 2 (set-dez, 1988).

CHAMBOULEYRON, Rafael. Escravos do Atlântico equatorial: tráfico negreiro para o Estado do Maranhão e Pará (século XVII e início do século XVIII). Rev. Bras. Hist., São Paulo, v. 26, n. 52, p. 79-114, Dec. 2006.

CHAMBOULEYRON, Rafael; BARBOSA, Benedito C. Costa; BOMBARDI, Fernanda Aires; SOUSA, Claudia Rocha de. 'Formidável contágio': epidemias, trabalho e recrutamento na Amazônia colonial (1660-1750). História, Ciências, Saúde-Manguinhos, v. 18, p. 987-1004, 2011.

CHAMBOULEYRON, Rafael. O "senhor absoluto dos sertões". O "capitão preto" José Lopes, a Amazônia e o Cabo Verde. Boletin Americanista, v. 58, p. 55-72, 2008.

. O governo dos sertões. Açúcar, aguardente e índios na Amazônia Colonial. Texto apresentado no SEMINÁRIO DE ESTUDOS COLONIAIS/UFPA, outubro de 2007.

. Suspiros por um escravo de Angola. Discursos sobre a mão-de-obra africana na Amazônia seiscentista. Belém: Humânitas, vol.20, n 1/2 (2004), pp. 141-63.

Povoamento, Ocupação e Agricultura na Amazônia Colonial (1640-1706). Belém, Editora Açaí, 2010.p .17.

CHAMBOLEYRON, R; BOMBARDI, F. A. Descimentos privados de índios na Amazônia Colonial (séculos XVII e XVIIII). Varia História, 2011 vol.27, n.46. Disponível em: http://www.scielo.br/scielo.php?pid=S0104-8775201100020001 1\&script=sci_arttext. Acessado em: 28 jun.2020.

CHALHOUB, Sidney. Escravização ilegal e precarização da liberdade no Brasil império". In: AZEVEDO, Elciene et al. (orgs). Trabalhadores na cidade. Cotidiano e cultura no Rio de Janeiro e em São Paulo, séculos XIX e XX. Campinas: Editora da Unicamp, 2009, pp. 23-62;

Precariedade estrutural: o problema da liberdade no Brasil escravista (século XIX). História Social. Campinas, n. 9, 2010, pp. 33-62;

. A Força da Escravidão. Ilegalidade e costume no Brasil oitocentista. São Paulo: Companhia das Letras, 2012.

BARBOSA, Benedito Carlos Costa. Braços negros na Amazônia: trabalho e economia no Estado do Maranhão e Grão-Pará 1707-1750. Monografia (Especialização em História), Universidade Federal do Pará, 2008.

. Em outras margens do atlântico: tráfico negreiro para o Estado do Maranhão e GrãoPará (1707-1750). Belém: Dissertação (Mestrado em História) Universidade Federal do Pará, 2009.

BEZERRA NETO, José Maia. Escravidão Negra no Pará (séculos XVII-XIX), $2^{\circ}$ ed. Belém: Paka Tatu, 2012.

Revista da ABPN • v. 12, n. Ed. Especial - Caderno Temático: "Africanos, escravizados, libertos biografias, imagens e experiências atlânticas” • agosto de 2020, p. $10-26$ 
BOMBARDI, Fernanda Pelos Interstícios do Olhar do Colonizador: Descimentos de Índios no Estado do Maranhão e Grão-Pará (1680-1750). Dissertação (Mestrado em História) Universidade de São Paulo, 2014.

CARDOSO, Claudia Pons. Experiências de Mulheres Negras e o Feminismo Negro no Brasil. Revista da Associação Brasileira de Pesquisadores/as Negros/as (ABPN), [S.1.], v. 10, n. 25, p. 317-328, jun. 2018. ISSN 2177-2770. Disponível em: <http://abpnrevista.org.br/revista/index.php/revistaabpn1/article/view/618>. Acesso em: 09 jul. 2020 .

DIAS, Camila Loureiro; BOMBARDI, Fernanda Aires. o que dizem as licenças? Flexibilização da legislação e recrutamento particular de trabalhadores indígenas no Estado do Maranhão (1680-1755). Rev. Hist. (São Paulo), São Paulo, n. 175, p. 249-280, Dec. 2016.

. L'Amazonie Avant Pombal. Économie, Politique, Territoire.Tese (Doutorado em História e Civilização), École des Hautes Études em Sciences Sociales. 2014.

GOMES, Flávio dos Santos. A Hidra e os Pântanos: quilombos e mocambos no Brasil (sécs. XVII-XIX). Campinas-SP, 1997.

FARAGE, Nádia. As muralhas dos sertões: os povos indígenas no rio Branco e a colonização. Rio de Janeiro: Paz e Terra; ANPOCS, 1991.

FLORENTINO, Manolo. Em costas negras: uma história do tráfico de escravos entre a África e o Rio de Janeiro (séculos XVIII e XIX). São Paulo: Companhia das Letras, 1997.

FLORENTINO, Manolo; RIBEIRO, Alexandre Vieira; SILVA, Daniel Domingues da. Aspectos comparativos do tráfico de africanos para o Brasil (séculos XVIII e XIX). Afro-Ásia, 31 (2004).

HAWTHORNE, Walter. From Africa to Brazil: Culture, Identity, and an Atlantic Slave Trade, 1600-1830". New York: Cambridge University Press, 2010.

HORTA, José da Silva. "O nosso Guiné": representações luso-africanas do espaço guineense (sécs. XVI-XVII)". Actas do Congresso Internacional O ESPAÇO ATLÂNTICO DE ANTIGO REGIME: PODERES E SOCIEDADES (Lisboa, 2-5 de Novembro de 2005, FCSH da Universidade Nova de Lisboa, organizado pelo Centro de Estudos de História de Além-Mar e pelo Instituto de Investigação Científica Tropical), Instituto de Investigação Científica Tropical e Centro de História de Além-Mar, 2009.

LOPES, Carlos. O Kaabu e os seus vizinhos: uma leitura espacial e histórica explicativa de conflitos. Afro- Asia, vol, 32, (2005).

LOPES, Gustavo Acioli. Negócio da Costa da Mina e comércio atlântico: tabaco, açúcar, ouro e tráfico de escravos: Pernambuco (1654-1760). Tese (Doutorado em História), Universidade de São Paulo, 2008.

LOPES, Gustavo Acioli \& MENZ, Maximiliano M. Resgate e mercadorias: uma análise comparada do tráfico luso-brasileiro em Angola e na Costa da Mina (século XVIII). Afro-Ásia, $\mathrm{n}^{\mathrm{o}} 37,2008$.

Revista da ABPN • v. 12, n. Ed. Especial - Caderno Temático: "Africanos, escravizados, libertos biografias, imagens e experiências atlânticas" • agosto de 2020, p. $10-26$ 
KARASCH. Mary C., Slave Life in Rio de Janeiro, 1808-1850 (Princeton University Press, Princeton, 1987.

MATTOSO, Kátia. Ser escravo no Brasil. São Paulo: Brasiliense, 2003.

MELLO, Márcia Eliane A. Souza e. Desvendando outras Franciscas: Mulheres cativas e as ações de liberdade na Amazônia colonial portuguesa. Portuguese Studies Review 13 (2005): 116.

Para servir a quem quiser: apelação de liberdades dos índios na Amazônia Portuguesa'. In: Sampaio, P. M.; Erthal, R. C. (Org.). Rastros da Memória: histórias e trajetórias das populações indígenas na Amazônia. Manaus: EDUA, 2006, p. 48-72.

Fé e império: As Juntas das Missões nas conquistas portuguesas. Manaus: EdUA/FAPEAM, 2009.

O Regimento do Procurador dos Índios do Estado do Maranhão. Outros Tempos, vol.9, no14 (2012): 222-231. Disponível em: http://www.outrostempos.uema.br/OJS/index.php/outros tempos_uema/issu e/view/6. Acessado em: 27 de maio de 2020.

MELO, Vanice Siqueira de. Cruentas guerras: índios e portugueses no sertão do Maranhão e Piauí (primeira metade do século XVIII).Curitiba, editora : Prisma 2017.

MELLO, Isabele de Matos Pereira de. Os Ministros da Justiça na América Portuguesa: Ouvidores-Gerais e Juízes de Fora na Administração Colonial (SÉC. XVIII). Rev. Hist. (São Paulo), São Paulo, n. 171, p. 351-381

OLIVEIRA, Maria Inês Cortês de. Quem eram os, negros da Guiné? A Origem dos Africanos na Bahia. Afro-Ásia. Salvador, n. 19/20, 1997, p. 3774.

PARÉS, Luis Nicolau. A Formação do Candomblé: história e ritual da nação jeje na Bahia. Campinas/SP. Editora Unicamp, 2 ed.rev.2007.

PEREIRA, Manuel Nunes. A introdução do negro na Amazônia. Boletim Geográfico IBGE. vol.7, $\mathrm{n}^{\circ} 77$ (1949), p. 510.

PINHEIRO, Fernanda Aparecida Domingos. Confrades dos Rosário: sociabilidade e identidade étnica em Mariana - Minas Gerais (1745-1820). Dissertação (Mestrado em História) Universidade Federal Fluminense: Niterói, 2006.

RACHI, Silvia. Por mãos alheias: usos da escrita na sociedade colonial. Belo Horizonte: Editora PUC MINAS, 2016.

REIS, João José. Rebelião escrava no Brasil: a história do levante dos malês (1835), São Paulo, Brasiliense, 1986

REIS, Arthur Cezar Ferreira. O negro na empresa colonial dos portugueses na Amazônia. ACTAS DO CONGRESSO INTERNACIONAL DE HISTÓRIA DOS DESCOBRIMENTOS. Lisboa: Comissão Executiva das Comemorações da Morte do Infante Dom Henrique, vol. V, III parte, 1961.

RODNEY, Walter. A History of Upper Guinea Coast 1545-1800, Oxford, Clarendon Press, 1970.

Revista da ABPN • v. 12, n. Ed. Especial - Caderno Temático: "Africanos, escravizados, libertos biografias, imagens e experiências atlânticas" • agosto de 2020, p. $10-26$ 
SAMPAIO, Patrícia Melo. Administração colonial e legislação indigenista na Amazônia portuguesa. In: Mary del PRIORE \& Flávio dos Santos GOMES (Orgs.). Os Senhores dos Rios. Amazônia, margens e histórias. Rio de Janeiro: Elsevier, 2003.

SALLES, Vicente. $O$ negro no Pará: sob o regime de escravidão. $3^{a}$ edição. Belém: IAP; Programa Raízes, 2005.

SCHWARCZ, Lília; GOMES, Flávio (orgs.). Dicionário da Escravidão e Liberdade, São Paulo: Companhia da Letras, 2018,

SILVA, Daniel B. Domingues. The Atlantic Slave Trade to Maranhão, 1680 - 1846: volume, routes an organization. Slaveryan Abolition, vol. 29, No. 4dezember 2008, pp. 477-501.

SOARES, Mariza. Mina, Angola e Guiné: Nomes d'África no Rio de Janeiro Setecentista. In.: Tempo. Vol. 3, $\mathrm{n}^{\circ}$, dezembro de 1998.

. (org.) Rotas Atlânticas da Diáspora Africana: da Baia do Benim ao Rio de Janeiro. Niterói: EduFF, 2007.

. Devotos da Cor. Identidade étnica, religiosidade e escravidão no Rio de Janeiro, século XVIII. Rio de Janeiro: Civilização Brasileira, 2000.

VERGER, Pierre. Fluxo e refluxo do tráfico de escravos entre o golfo de Benin e a Baía de Todos os Santos: dos séculos XVII a XIX. São Paulo: Corrupio, 1987.

Recebido 03/07/2020

Aprovado em 22/07/2020

Revista da ABPN • v. 12, n. Ed. Especial - Caderno Temático: "Africanos, escravizados, libertos biografias, imagens e experiências atlânticas" • agosto de 2020, p. $10-26$ 